\title{
Reduction Characteristics of Pure Gale Limonite Pellets in Gaseous Environments
}

\author{
Guofeng Gao ${ }^{1,2}$, Xiaolei Zhou ${ }^{1,2, *}$, Zhe $\mathrm{Shi}^{1,2}$ and Lanpeng Liu ${ }^{1,2}$ \\ ${ }^{1}$ Faculty of Metallurgical and Energy Engineering, Kunming University of Science and Technology, Yunnan Kunming 650093, China \\ ${ }^{2}$ Clean Metallurgy Key Laboratory of Complex Iron Resources, Kunming University of Science and Technology, \\ Yunnan Kunming 650093, China
}

\begin{abstract}
In this study, the isothermal reduction mechanism of limonite, an important iron ore resource, in $\mathrm{H}_{2}$, $\mathrm{CO}$, and a mixed atmosphere of both gases was studied as a function of reduction temperature and gas composition. The kinetics of the reduction process were studied using a shrinking kernel model. The experimental results show that the degree of reduction of the oxidized pellet particles increases with increases in both reduction time and temperature. Also, it has been found that an increase in the ratio of $\mathrm{H}_{2} /\left(\mathrm{H}_{2}+\mathrm{CO}\right)$ and an increase in temperature result in shortened reduction times. During the reduction process, the kinetic studies show that the early stage of the gas reduction process is controlled by the interfacial chemical reaction and later stages are controlled by diffusion. SEM results show that the particles reduced in the $\mathrm{H}_{2}$ atmosphere have many micropores. Providing a gas passage during the reduction process reduces the gas diffusion resistance and promotes the diffusion reaction. [doi:10.2320/matertrans.MT-M2019311]
\end{abstract}

(Received October 25, 2019; Accepted May 12, 2020; Published August 25, 2020)

Keywords: limonite, reduction, oxidized pellets, kinetics

\section{Introduction}

The steel industry is one of the most energy-consuming manufacturing industries, where $50 \%$ to $70 \%$ of the total energy consumption in China is attributed to this industry. Iron ore and coke are the main raw materials for steel production. Due to the gradual increase in demand and years of development and utilization, the availability and access to high-quality iron ore and coke have been further reduced. ${ }^{1-4)}$ The traditional blast furnace has many adverse properties such as long process times, expensive investment, high energy consumption, and the need for high-grade ore inputs (low grades cannot typically be utilized). All these lead to challenges for the sustainable development of the steel industry. ${ }^{5-7)}$ Compared with traditional blast furnace ironmaking technology, the direct reduction process has been considered as a promising steel production method.

In recent years, domestic and foreign experts have done a lot of research on the mechanism and kinetics of iron ore in a mixed atmosphere of $\mathrm{CO}, \mathrm{H}_{2}$ and $\mathrm{CO}-\mathrm{H}_{2}$ both experimentally and theoretically. ${ }^{8-12)}$ However, most of the previous studies have focused on the reduction process of magnetite and hematite, and there are few studies on the reduction process of pure limonite pellets. Keisuke Abe et al. ${ }^{13)}$ found that $\mathrm{FeOOH}$ was completely converted to $\mathrm{Fe}_{2} \mathrm{O}_{3}$ in limonite during dehydration. Due to the introduction of nanopores in limonite, the specific surface area of limonite increased. $\mathrm{R}$. Sah et al. $^{14)}$ found that as pellet porosity increased, the internal surface area available for reduction and the degree of reduction increased. This showed that oxidized limonite pellets were easier to reduce. Yang Lu et al. ${ }^{15)}$ studied the reduction and carbon deposition behavior of porous limonite powder during isothermal reduction. The results showed that $\mathrm{CO}$ concentration and reaction temperature had significant effects on the reduction degree and rate.

In production, limonite is mostly used in combination with other ores, such as sintered ore. The reduction reaction kinetics of pure limonite pellets has not been systematically studied. To study the effects of gas composition and temperature on the reduction characteristics of pure limonite pellets, these properties at different temperatures and atmospheres were studied by thermogravimetric analysis. After calculating various properties, the reduced pellets were analyzed by scanning electron microscopy. These findings will provide a technical basis for the industrialization of gasbased limonite pellet reduction.

\section{Materials and Methods}

\subsection{Preparation of pure limonite pellets}

The limonite samples used in this study were from Chinese steel mills. The crystalline phase of the sample was characterized by X-ray diffraction (XRD). The XRD pattern of limonite is shown in Fig. 1(a), where the main mineral form of limonite is $\mathrm{FeOOH}$, which contains a large amount of crystalline water.

The preparation method of the calcined pellets is as follows: first, 100-200 mesh Guisha limonite is mixed with $1.48 \%$ bentonite at certain ratios. Then $3 \%$ distilled water was added for wetting, 7\% water was sprayed for pelleting, and the pellets were screened for a diameter of $10 \mathrm{~mm}-$ $12 \mathrm{~mm}$ in the crucible. The temperature was increased from room temperature to $1558 \mathrm{~K}$ at a heating rate of $20 \mathrm{~K} / \mathrm{min}$, maintained for 19 minutes, and then the air was removed with a vacuum. The main chemical components of the calcined pellets are shown in Table 1. The XRD patterns of the pellets after calcination are shown in Fig. 1(b), where the main phase was shown to be $\mathrm{Fe}_{2} \mathrm{O}_{3}$, illustrating that $\mathrm{FeOOH}$ was converted into $\mathrm{Fe}_{2} \mathrm{O}_{3}$ during the calcination. During roasting of limonite, the crystallization water will decompose, making the specific surface area of pellets larger after roasting. ${ }^{16)}$ Due to the larger specific surface area of iron ore, the reduction rate is increased, ${ }^{17)}$ so the reduction rate of limonite is higher than other ores. 



Fig. 1 XRD pattern of: (a) limonite and (b) oxidized pellets.

Table 1 Chemical constituents of oxidized limonite pellets (wt\%).

\begin{tabular}{lllllllllll}
\hline $\mathrm{TF}$ & $\mathrm{FeO}$ & $\mathrm{SiO}_{2}$ & $\mathrm{CaO}$ & $\mathrm{MgO}$ & $\mathrm{Al}_{2} \mathrm{O}_{3}$ & $\mathrm{MnO}$ & $\mathrm{TiO}_{2}$ & $\mathrm{~K}_{2} \mathrm{O}$ & $\mathrm{As}$ & $\mathrm{V}_{2} \mathrm{O}_{5}$ \\
\hline 61.30 & 1.68 & 4.74 & 0.12 & 0.01 & 0.01 & 4.01 & 0.18 & 0.082 & 0.187 & 0.043 \\
\hline
\end{tabular}

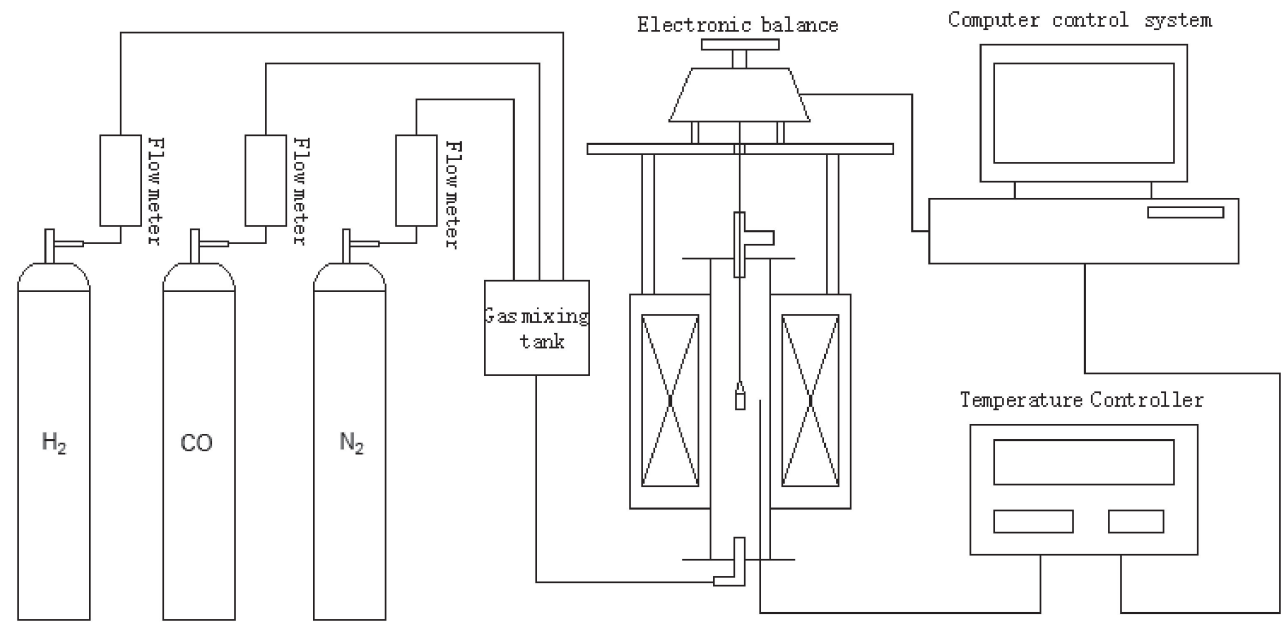

Fig. 2 Testing device diagram.

\subsection{Reduction process}

The experimental setup is shown in Fig. 2. The heating device uses a vertical resistance furnace (Shanghai Yifeng Electric Furnace Limited). The total power is $2 \mathrm{~kW}$, and a corundum tube with an inner diameter of $50 \mathrm{~mm}$ was used as the reduction reaction chamber, where the weight range was 0 210 g. The FA2104 electronic balance (Shanghai Hanyu Hengping Scientific Instrument Limited) has an accuracy of $0.1 \mathrm{mg}$ for precise measurement capabilities. Data acquisition is connected to the computer by an RS232 interface with a time interval of one min, which achieves real-time collection of experimental data.

Before the experiment, the reactor was charged with nitrogen to check for leaks. When it was determined that there was no air leakage, the basket with the pellets was placed in the furnace, and the upper hook was hung on the bottom of the balance. The tube furnace was powered on and the connected computer program began heating the furnace. The reactor was filled with nitrogen throughout the temperature rise. When the temperature reached the setpoint, the electronic balance was turned on to begin data collection. Then the reducing gas $\left(\mathrm{H}_{2}, \mathrm{CO}\right)$ was charged into the system.
Once the experiment was complete, the reducing gas $\left(\mathrm{H}_{2}\right.$, $\mathrm{CO}$ ) flow stopped, and the system was purged with nitrogen. The system was cooled to room temperature under nitrogen protection to prevent oxidation of the sample in air.

The calculation of the degree of reduction of the limonite pellets after calcination is shown in eq. (1): ${ }^{18)}$

$$
\begin{aligned}
\mathrm{R} & =\frac{\mathrm{m}\left(\mathrm{O}_{\mathrm{L}}\right)}{\mathrm{m}_{0}\left(\mathrm{O}_{\mathrm{L}}\right)} \\
& =\left(\frac{0.11 \mathrm{w}(\mathrm{FeO})}{0.43 \mathrm{w}(\mathrm{TFe})}+\frac{\mathrm{m}_{1}-\mathrm{m}_{2}}{\mathrm{~m}_{1} \times 0.43 \mathrm{w}(\mathrm{TFe})} \times 100\right) \times 100 \%
\end{aligned}
$$

where $\mathrm{R}$ is the degree of reduction of iron, $\mathrm{m}_{0}\left(\mathrm{O}_{\mathrm{L}}\right)$ is the total mass of metallic Fe combined with $\mathrm{O}$ in the limonite pellet after calcination, and $\mathrm{m}\left(\mathrm{O}_{\mathrm{L}}\right)$ is the total mass loss of $\mathrm{O}$ combined with Metallic Fe. During the reduction process, $\mathrm{w}(\mathrm{TFe})$ and $\mathrm{w}(\mathrm{FeO})$ are the mass fractions of $\mathrm{TFe}$ and $\mathrm{FeO}$, respectively. In the calcination of limonite pellets, $\mathrm{m}_{1}$ is the mass of limonite pellets before reduction, and $m_{2}$ is the mass of the limonite sphere during the reduction process. The 0.11 and 0.43 parameters represent the oxygen demand conversion coefficients for the conversion of $\mathrm{FeO}$ and Metallic $\mathrm{Fe}$ to $\mathrm{Fe}_{2} \mathrm{O}_{3}$. 


\subsection{Reduction thermodynamic analysis}

$\mathrm{Fe}_{2} \mathrm{O}_{3}$ is a high-valence oxide of iron, and the reduction of iron oxide is carried out step by step under $\mathrm{CO}$ atmosphere. Reduction of iron oxide-related reactions in a carbon monoxide (CO) atmosphere and its Gibbs free energy are shown in eqs. (2) to (11):

$\mathrm{T}>843 \mathrm{~K}$,

$$
\begin{gathered}
3 \mathrm{Fe}_{2} \mathrm{O}_{3}+\mathrm{CO}=2 \mathrm{Fe}_{3} \mathrm{O}_{4}+\mathrm{CO}_{2} \\
\Delta_{\mathrm{r}} \mathrm{G}_{\mathrm{m}}^{\theta}=-52131-41.0 \mathrm{~T} \mathrm{~J} / \mathrm{mol} \\
\mathrm{Fe}_{3} \mathrm{O}_{4}+\mathrm{CO}=3 \mathrm{FeO}+\mathrm{CO}_{2} \\
\Delta_{\mathrm{r}} \mathrm{G}_{\mathrm{m}}^{\theta}=35380-4.16 \mathrm{~T} \mathrm{~J} / \mathrm{mol} \\
\mathrm{FeO}+\mathrm{CO}=\mathrm{Fe}+\mathrm{CO}_{2} \\
\Delta_{\mathrm{r}} \mathrm{G}_{\mathrm{m}}^{\theta}=-22880+24.26 \mathrm{~T} \mathrm{~J} / \mathrm{mol}
\end{gathered}
$$

$\mathrm{T}<843 \mathrm{~K}$

$$
\begin{gathered}
3 \mathrm{Fe}_{2} \mathrm{O}_{3}+\mathrm{CO}=2 \mathrm{Fe}_{3} \mathrm{O}_{4}+\mathrm{CO}_{2} \\
\Delta_{\mathrm{r}} \mathrm{G}_{\mathrm{m}}^{\theta}=-52131-41.0 \mathrm{~T} \mathrm{~J} / \mathrm{mol} \\
\frac{1}{4} \mathrm{Fe}_{3} \mathrm{O}_{4}+\mathrm{CO}=\frac{3}{4} \mathrm{Fe}+\mathrm{CO}_{2} \\
\Delta_{\mathrm{r}} \mathrm{G}_{\mathrm{m}}^{\theta}=-9832+8.58 \mathrm{~T} \mathrm{~J} / \mathrm{mol}
\end{gathered}
$$

It can be seen from the direct reduction reaction that the number of moles of gas before and after the reaction does not change, which indicates that the gas pressure does not change before and after the direct reduction reaction, and the pressure does not affect the reduction process. The thermodynamic calculation of CO-reduced iron oxides was carried out by a thermodynamic database, and the equilibrium relationship is shown in Fig. 3.

As seen in the reaction curve, in the reduction process of iron oxide by carbon, $\mathrm{Fe}_{2} \mathrm{O}_{3}$ generates $\mathrm{Fe}_{3} \mathrm{O}_{4}, \mathrm{Fe}_{3} \mathrm{O}_{4}$ generates metallic $\mathrm{Fe}$ or $\mathrm{FeO}$, and $\mathrm{FeO}$ generates metallic Fe. The reaction curve of $\mathrm{FeO}$ to metallic $\mathrm{Fe}$ shows an increased slope as temperature increases, indicating that the reaction is exothermic. The $\mathrm{FeO}$ reaction curve of $\mathrm{Fe}_{3} \mathrm{O}_{4}$ shows a decreasing slope as temperature increases. This shows that the reaction is absorbing heat due to the direct reduction reaction to obtain valuable metallic iron. It can be seen from the reaction that in the process of reducing iron oxide by $\mathrm{CO}$, the gas utilization rate decreases as temperature increases, but the increase in temperature helps to increase the kinetic conditions of the direct reduction reaction.

The reaction for reducing iron oxide in a hydrogen $\left(\mathrm{H}_{2}\right)$ atmosphere is as shown in formulas (12) to (21): $\mathrm{T}>843 \mathrm{~K}$,

$$
\begin{gathered}
3 \mathrm{Fe}_{2} \mathrm{O}_{3}+\mathrm{H}_{2}=2 \mathrm{Fe}_{3} \mathrm{O}_{4}+\mathrm{H}_{2} \mathrm{O} \\
\Delta_{\mathrm{r}} \mathrm{G}_{\mathrm{m}}^{\theta}=-15547+74.40 \mathrm{~T} \mathrm{~J} / \mathrm{mol} \\
\mathrm{Fe}_{3} \mathrm{O}_{4}+\mathrm{H}_{2}=3 \mathrm{FeO}+\mathrm{H}_{2} \mathrm{O} \\
\Delta_{\mathrm{r}} \mathrm{G}_{\mathrm{m}}^{\theta}=71940-73.62 \mathrm{~T} \mathrm{~J} / \mathrm{mol} \\
\mathrm{FeO}+\mathrm{H}_{2}=\mathrm{Fe}+\mathrm{H}_{2} \mathrm{O} \\
\Delta_{\mathrm{r}} \mathrm{G}_{\mathrm{m}}^{\theta}=23430-16.16 \mathrm{~T} \mathrm{~J} / \mathrm{mol}
\end{gathered}
$$

$\mathrm{T}<843 \mathrm{~K}$

$$
\begin{gathered}
3 \mathrm{Fe}_{2} \mathrm{O}_{3}+\mathrm{H}_{2}=2 \mathrm{Fe}_{3} \mathrm{O}_{4}+\mathrm{H}_{2} \mathrm{O} \\
\Delta_{\mathrm{r}} \mathrm{G}_{\mathrm{m}}^{\theta}=-15547+74.40 \mathrm{~T} \mathrm{~J} / \mathrm{mol} \\
\frac{1}{4} \mathrm{Fe}_{3} \mathrm{O}_{4}+\mathrm{H}_{2}=\frac{3}{4} \mathrm{Fe}+\mathrm{H}_{2} \mathrm{O} \\
\Delta_{\mathrm{r}} \mathrm{G}_{\mathrm{m}}^{\theta}=35550-30.40 \mathrm{~T} \mathrm{~J} / \mathrm{mol}
\end{gathered}
$$

Thermodynamic calculations of $\mathrm{H}_{2}$-reduced iron oxides were performed by a thermodynamic database, and the equilibrium relationship is shown in Fig. 4. Similar to the reduction by $\mathrm{CO}$, the gas phase equilibrium diagram is divided into four regions. From bottom to top, they are the $\mathrm{Fe}_{2} \mathrm{O}_{3}$ stable region, $\mathrm{Fe}_{3} \mathrm{O}_{4}$ stable region, $\mathrm{FeO}$ stable region, and the metallic Fe stable region.

It is shown from the reaction curves in the figure that in the process of reducing iron oxide by $\mathrm{H}_{2}$, all reaction curves show decreasing slope as temperature increases, indicating that the reactions are all endothermic reactions (except $\mathrm{Fe}_{2} \mathrm{O}_{3}$, which is not formed in this reduction process). It can be seen from the reaction that the gas utilization rate of $\mathrm{H}_{2}$-reduced iron oxide increases with increasing temperature, which is opposite to the thermodynamic characteristics of CO-reduced iron oxide. The temperature rise enhances the kinetic conditions of the direct reduction reaction. Combined with the thermodynamic and kinetic properties of $\mathrm{H}_{2}$-reduced iron oxides, it is known that the temperature increase will significantly promote the reduction of iron oxides by $\mathrm{H}_{2}$.

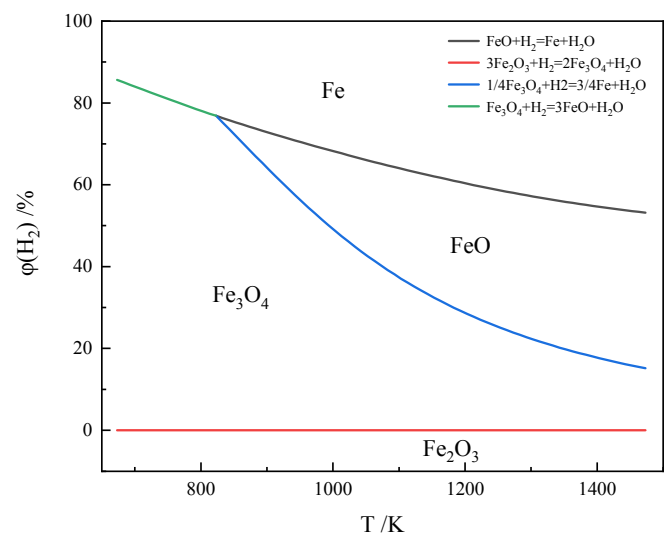

Fig. 4 Relationship between gas-phase composition and temperature of $\mathrm{H}_{2}$-reduced iron oxide.
Fig. 3 Relationship between the gas-phase composition and temperature of

CO-reduced iron oxide.

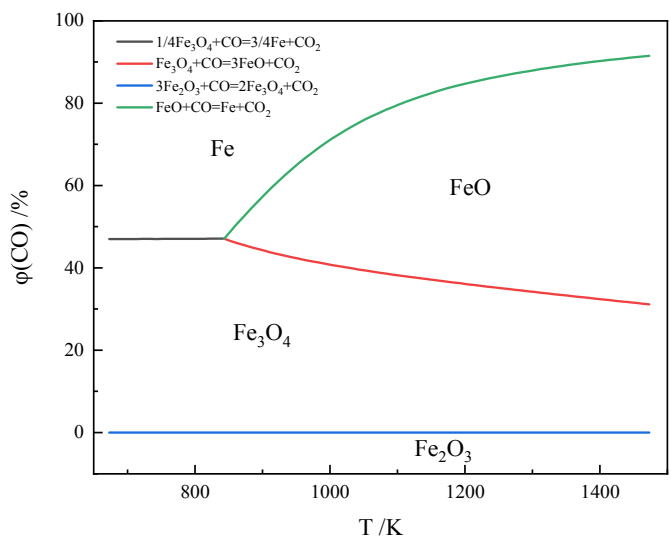



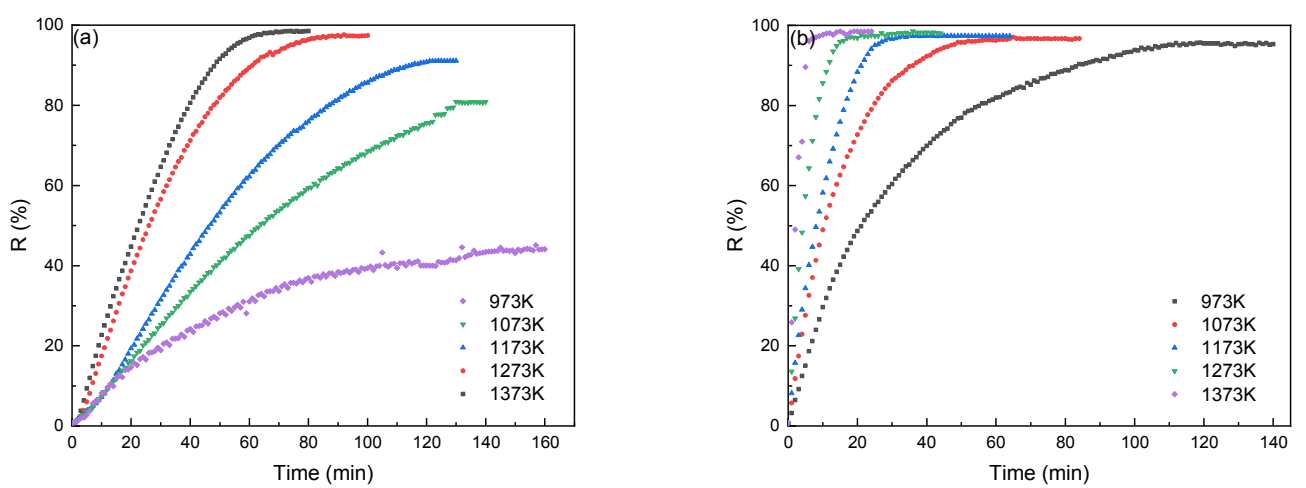

Fig. 5 Reduction degree curves of oxidized pellets at $973 \mathrm{~K} \sim 1373 \mathrm{~K}$ with (a) $\mathrm{CO}$ and (b) $\mathrm{H}_{2}$.

\subsection{Reduction kinetic analysis}

According to previous studies, it can be concluded ${ }^{19-21)}$ that the reduction process of limonite pellets after calcination is controlled by non-local chemical reactions. Therefore, the model used to describe the iron ore reduction kinetics is an unreacted nuclear model. The model includes the external diffusion process of gas, the interfacial chemical reaction process and the internal diffusion process of gaseous materials. ${ }^{22)}$ The total reduction time of the limonite pellets under $\mathrm{H}_{2}$ and $\mathrm{CO}$ atmospheres can be expressed by eq. (22). ${ }^{23)}$ Based on the unreacted contraction nucleus model, the rate equation is as shown in eqs. (23) and (24). ${ }^{24)}$

$$
\begin{aligned}
\mathrm{t}= & \frac{\mathrm{r}_{0} \rho_{0}}{\mathrm{k}_{0}\left(\mathrm{c}_{0}-\mathrm{c}_{\mathrm{q}}\right)}\left[1-(1-\mathrm{R})^{\frac{1}{3}}\right] \\
& +\frac{\mathrm{r}_{0}^{2} \rho_{0}}{\mathrm{D}_{\mathrm{e}}\left(\mathrm{c}_{0}-\mathrm{c}_{\mathrm{q}}\right)}\left[1-\frac{2}{3} \mathrm{R}-(1-\mathrm{R})^{\frac{2}{3}}\right]
\end{aligned}
$$

Interface chemical reaction control:

$$
1-(1-\mathrm{R})^{\frac{1}{3}}=\mathrm{kt}
$$

Diffusion control:

$$
1-\frac{2}{3} \mathrm{R}-(1-\mathrm{R})^{\frac{2}{3}}=\mathrm{kt}
$$

where $t$ is the minimum reduction time, $r_{0}$ is the initial feature radius $(\mathrm{cm})$ of the pellet. $\rho_{0}$ is the initial oxygen concentration of the pellet $\left(\mathrm{mol} / \mathrm{cm}^{3}\right), \mathrm{k}_{0}$ is a parameter constant, $\mathrm{c}_{0}$ and $\mathrm{c}_{\mathrm{q}}$ are the reducing gas concentration $\left(\mathrm{mol} / \mathrm{cm}^{3}\right)$ at the surface and equilibrium of the pellet particles. $\mathrm{R}$ is the degree of reduction, $D_{e}$ is the effective diffusion coefficient $\left(\mathrm{cm}^{2} / \mathrm{min}\right)$, and $\mathrm{k}$ is the reduction rate constant $(\mathrm{cm} / \mathrm{min})$.

Based on eq. (22), different curves were plotted to study the pellet particle reduction control process. If the interfacial chemical reaction is a controlled process, it is plotted by $1-(1-\mathrm{R})^{\frac{1}{3}}$ and time $\mathrm{t}$. If the gas diffusion process is controlled, $1-\frac{2}{3} \mathrm{R}-(1-\mathrm{R})^{\frac{2}{3}}$ is plotted against time $\mathrm{t}$ to obtain the target curve.

\section{Results and Discussion}

\subsection{Influence of process parameters on the pellet reducing ability}

The effects of experimental parameters such as reduction temperature, gas composition, and reduction time on the reducing degree of pure limonite pellets after calcination were studied.

\subsubsection{Reducing temperature}

To understand the effects of temperature, the experiment was carried out every $100 \mathrm{~K}$ in the range of $973 \mathrm{~K}-1373 \mathrm{~K}$, and the total gas flow rate was $3 \mathrm{~L} / \mathrm{min}$ (the flow velocity in the tube was $0.382 \mathrm{~m} / \mathrm{min}$ ). The pellet diameter was $10.5 \pm$ $0.5 \mathrm{~mm}$. Figures 5(a) and (b) are the reducing curves of pure limonite pellets after calcination in pure $\mathrm{CO}$ and pure $\mathrm{H}_{2}$ at different temperatures.

The reduction of pure limonite pellets after calcination gradually increases with increasing reduction time. Under $\mathrm{CO}$, reductions were performed at $973 \mathrm{~K}, 1073 \mathrm{~K}, 1173 \mathrm{~K}$, $1273 \mathrm{~K}$, and $1373 \mathrm{~K}$, and the degrees of reduction were $36.6 \%, 75.6 \%, 91.0 \%, 97.6 \%$, and $98.5 \%$, respectively. Under $\mathrm{H}_{2}$, reductions were carried out at $973 \mathrm{~K}, 1073 \mathrm{~K}$, $1173 \mathrm{~K}, 1273 \mathrm{~K}$ and $1373 \mathrm{~K}$, and the degrees of reduction were $95.5 \%, 96.4 \%, 97.3 \%, 97.7 \%$, and $98.5 \%$, respectively. The results show that the reduction temperature has a significant effect on the degree of pellet reduction. This is because the mineral lattice has higher energy at higher temperatures. ${ }^{25)}$ For $\mathrm{H}_{2}$, calculations show that increasing temperature thermodynamically favor iron oxide reduction.

Under the $\mathrm{CO}$ reducing atmosphere, a kinetic analysis of the pellet ore reduction process was carried out based on formulas (23) and (24). The pure, oxidized limonite pellet particles are shown in Fig. 6. It can be found in Figs. 6(a) and $6(\mathrm{~b})$ that the pure limonite pellet after calcination is divided into two stages: early stage and late stage. The results show that the pure, oxidized limonite pellets are controlled by the interfacial chemical reaction and diffusion in the early and late stages, respectively. The reduction rate constants for the two stages are shown in Table 2. The rate constant increases as the temperature increases, which indicates that increasing the temperature under $\mathrm{CO}$ favors pellet reduction.

The kinetic analysis of the pellet ore reduction process was carried out based on formulas (23) and (24) under an $\mathrm{H}_{2}$ reducing atmosphere. The pure, oxidized limonite pellet particles are shown in Fig. 7. It can be found in Figs. 7(a) and 7(b) that the whole reduction process of pure limonite pellets after calcination is divided into two stages: early stage and late stage. The results show that the reduction process of pure, oxidized limonite pellets is controlled by the interfacial chemical reaction. The reduction rate constants are shown in 



Fig. 6 Reduction degree curves of oxidized pellets at $1373 \mathrm{~K}$ with CO. (a) the plot of $1-(1-\mathrm{R})^{\frac{1}{3}}$ vs. time and (b) plot of $1-\frac{2}{3} R-(1-R)^{\frac{2}{3}}$ vs. time.

Table 2 Reduction rate of $973 \mathrm{~K}-1373 \mathrm{~K}$ oxidized pellets in CO.

\begin{tabular}{llllll}
\hline temperature & $973 \mathrm{~K}$ & $1073 \mathrm{~K}$ & $1173 \mathrm{~K}$ & $1273 \mathrm{~K}$ & $1373 \mathrm{~K}$ \\
\hline $\begin{array}{l}\text { Interface reaction } \\
\text { control }\end{array}$ & 0.00117 & 0.00326 & 0.00511 & 0.00933 & 0.0121 \\
\begin{tabular}{l} 
Diffusion control \\
\hline
\end{tabular} & $1.12 \times 10^{-4}$ & $3.85 \times 10^{-4}$ & $5.73 \times 10^{-4}$ & $8.71 \times 10^{-4}$ & $10.40 \times 10^{-4}$ \\
\hline
\end{tabular}
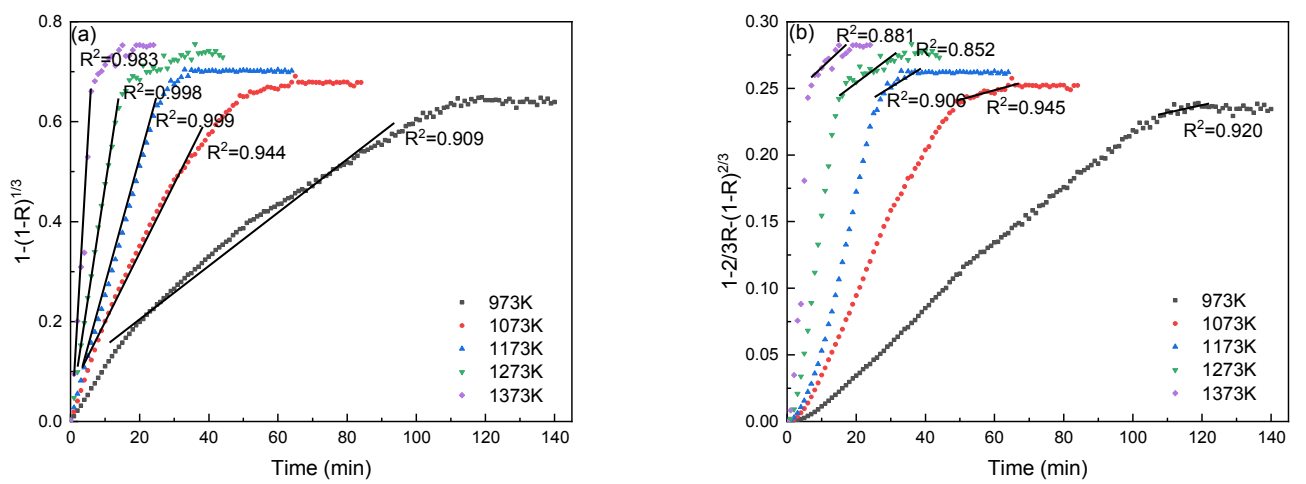

Fig. 7 Reduction degree curves of oxidized pellets at $1373 \mathrm{~K}$ with $\mathrm{H}_{2}$. (a) the plot of $1-(1-\mathrm{R})^{\frac{1}{3}}$ vs. time and (b) plot of $1-\frac{2}{3} R-(1-R)^{\frac{2}{3}}$ vs. time.

Table 3 Reduction rate of $973 \mathrm{~K}-1373 \mathrm{~K}$ oxidized pellets in $\mathrm{H}_{2}$ atmosphere.

\begin{tabular}{llllll}
\hline temperature & $973 \mathrm{~K}$ & $1073 \mathrm{~K}$ & $1173 \mathrm{~K}$ & $1273 \mathrm{~K}$ & $1373 \mathrm{~K}$ \\
\hline $\begin{array}{l}\text { Interface reaction } \\
\text { control }\end{array}$ & 0.00539 & 0.01262 & 0.02526 & 0.04633 & 0.10647 \\
$\begin{array}{l}\text { Diffusion control } \\
7.08 \times 10^{-4}\end{array}$ & $9.54 \times 10^{-4}$ & $17.40 \times 10^{-4}$ & $19.70 \times 10^{-4}$ & $28.40 \times 10^{-4}$ \\
\hline
\end{tabular}

Table 3. The rate constant increases as temperature increases, which indicates that elevated temperature in $\mathrm{H}_{2}$ favors pellet reduction.

According to the Arrhenius equation, the relationship between reaction temperature $(\mathrm{T})$ and the reduction rate constant $(\mathrm{k})$ can be obtained as shown in formula (25), where $E$ is the activation energy $(\mathrm{kJ} / \mathrm{mol})$ and $\mathrm{k}_{0}$ is the frequency factor.

$$
\mathrm{k}=\mathrm{k}_{0} \exp \left(-\frac{\mathrm{E}}{\mathrm{RT}}\right)
$$

Next, the natural logarithm is taken for eq. (25), which yields eq. (26):

$$
\ln \mathrm{k}=-\frac{\mathrm{E}}{\mathrm{RT}}+\ln \mathrm{k}_{0}
$$

The target curve is obtained by plotting $\ln \mathrm{k}$ as a function of $1 / \mathrm{T}$, and the reaction activity is obtained by the slope of the line. Figures 8 and 9 show the curves of $\ln \mathrm{k}$ and $1 / \mathrm{T}$ in $\mathrm{CO}$ and $\mathrm{H}_{2}$, respectively.

The relationship between $\ln \mathrm{k}$ and $1 / \mathrm{T}$ under $\mathrm{CO}$ is shown in Figs. 8(a) and 8(b). The activation energies of the early 



Fig. 8 Arrhenius plot of reaction degree constant k vs. temperature (a) intrinsic chemical reaction control step and (b) diffusion control step at $973 \mathrm{~K}-1373 \mathrm{~K}$ in $\mathrm{CO}$.


Fig. 9 Arrhenius plot of reaction degree constant k vs. temperature (a) intrinsic chemical reaction control step and (b) diffusion control step at $973 \mathrm{~K}-1373 \mathrm{~K}$ in $\mathrm{H}_{2}$.

Table 4 Activation energies of rate control steps in $\mathrm{CO}, \mathrm{H}_{2}$ reaction environments.

\begin{tabular}{lll}
\hline temperature & $\mathrm{CO} \mathrm{kJ} / \mathrm{mol}$ & $\mathrm{H}_{2} \mathrm{~kJ} / \mathrm{mol}$ \\
\hline Interface reaction control & 64.53 & 77.87 \\
Diffusion control & 44.59 & 38.99 \\
\hline
\end{tabular}

(interfacial chemical reaction control) and late (diffusion control) stages are $64.53 \mathrm{~kJ} / \mathrm{mol}$ and $44.59 \mathrm{~kJ} / \mathrm{mol}$. Therefore, the activation energy of the interfacial chemical reaction control is lower than the diffusion control phase.

The relationship between $\ln \mathrm{k}$ and $1 / \mathrm{T}$ under $\mathrm{H}_{2}$ is shown in Figs. 9(a) and 9(b). The activation energies of the early (interfacial chemical reaction control) and late (diffusion control) stages are $77.87 \mathrm{~kJ} / \mathrm{mol}$ and $38.99 \mathrm{~kJ} / \mathrm{mol}$. This shows that the activation energy of the interfacial chemical reaction control is higher than the diffusion control phase.

The activation energies of each stage in the $\mathrm{CO}$ and $\mathrm{H}_{2}$ atmospheres are shown in Table 4 . In the gas-based reduction process of the oxidized pellets, the activation energy in $\mathrm{H}_{2}$ in the early stage (interfacial reaction control) is higher than the activation energy of the same in $\mathrm{CO}$, and the activation energy in $\mathrm{H}_{2}$ in the later stage (diffusion control) is lower than that in the $\mathrm{CO}$ atmosphere. Compared with other iron ores, ${ }^{24)}$ limonite has similar activation energy in the interface chemical reaction stage, and its activation energy in the diffusion control stage is much less than that of other iron ore. This shows that reducing gas diffuses more easily in limonite pellets, which agrees with the characteristics of limonite.

\subsection{Single atmosphere micro analysis}

The effects of $\mathrm{CO}$ and $\mathrm{H}_{2}$ on the reduction of pure limonite pellets were studied. The morphologies of the pellets reduced at $1373 \mathrm{~K}$ in both $\mathrm{CO}$ and $\mathrm{H}_{2}$ are shown in Fig. 10. The reduced particles are looser than the original, and the pores are significantly larger. In comparing the $\mathrm{CO}$ reduction particles with the $\mathrm{H}_{2}$ reduction particles, it was found that the $\mathrm{CO}$ reduction particles have a tight grain structure with few channels inside the grains, and the $\mathrm{H}_{2}$ reduction particles have a loose structure with many pores inside the particles that allow for gas passage. The pores can reduce diffusion resistance during the reduction process.

Previous studies ${ }^{26}$ ) have shown that the molecular diameter of $\mathrm{H}_{2}$ is smaller than $\mathrm{CO}$ and can also reduce gas diffusion resistance during the reduction process. Therefore, $\mathrm{H}_{2}$ will rapidly diffuse inside the pellet to produce more pores, which 



Fig. 10 SEM images of particle samples: $(\mathrm{O})$ oxidized particles, (A) reducing particles in a CO atmosphere (Reduction temperature: $1373 \mathrm{~K}$ ), and (B) reducing particles in an $\mathrm{H}_{2}$ atmosphere (Reduction temperature: $1373 \mathrm{~K}$ ).

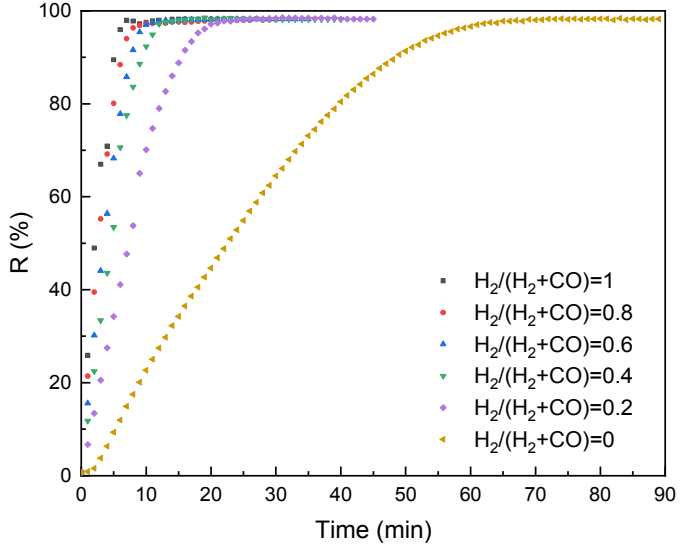

Fig. 11 Degree of reduction as a function of time at $1373 \mathrm{~K}$ in various gaseous environments.

induces a looser structure and further reduces the diffusion resistance of the pellet, thereby promoting the progress of the reduction reaction.

\subsection{Effect of mixed atmosphere on pellet reduction performance}

The gas component plays an important role in the oxidized pellet reduction process. The mixed gas of $\mathrm{H}_{2}$ and $\mathrm{CO}$ was used as the reducing gas. Due to the water gas shift reaction, the reduction of pellets will be significantly enhanced. ${ }^{27)}$ To determine the effect of gas composition on the degree of reduction, Fig. 11 shows the relationship between the degree of reduction, $\mathrm{R}$, and time, $\mathrm{t}$, at $1373 \mathrm{~K}$ at different $\mathrm{H}_{2}$ / $\left(\mathrm{H}_{2}+\mathrm{CO}\right)$ compositions.

To study the effects of gas composition on reduction kinetics, Fig. 12 shows the relationship between $1-(1-$ $\mathrm{R})^{\frac{1}{3}}$ and time, $\mathrm{t}$, at $1373 \mathrm{~K}$ at different $\mathrm{H}_{2} /\left(\mathrm{H}_{2}+\mathrm{CO}\right)$ gas compositions. The slope of the reaction curve was obtained by a linear regression method. Figure 13 shows the relationship between $1-\frac{2}{3} \mathrm{R}-(1-\mathrm{R})^{\frac{2}{3}}$ and time, $\mathrm{t}$, at $1373 \mathrm{~K}$, at different $\mathrm{H}_{2} /\left(\mathrm{H}_{2}+\mathrm{CO}\right)$ atmosphere compositions, where the slope was obtained by linear regression. The reaction rate constants under each experimental condition were calculated and shown in Table 5.

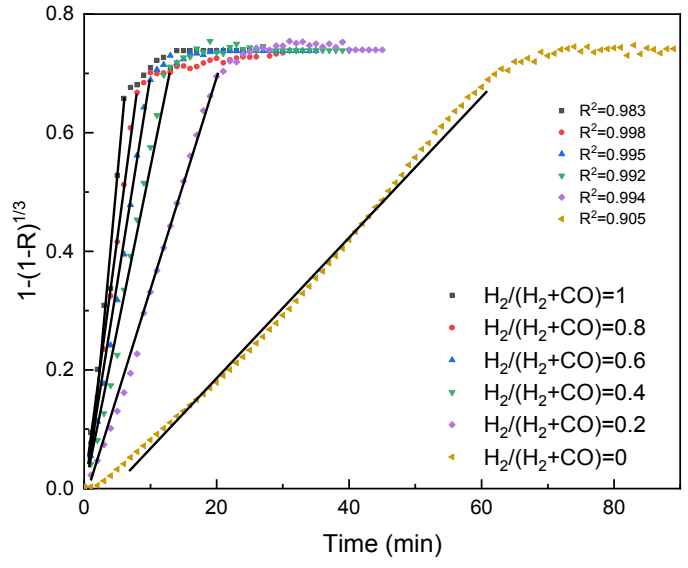

Fig. 12 Relationship between $1-(1-\mathrm{R})^{\frac{1}{3}}$ and time, $\mathrm{t}$, under different atmospheres at $1373 \mathrm{~K}$

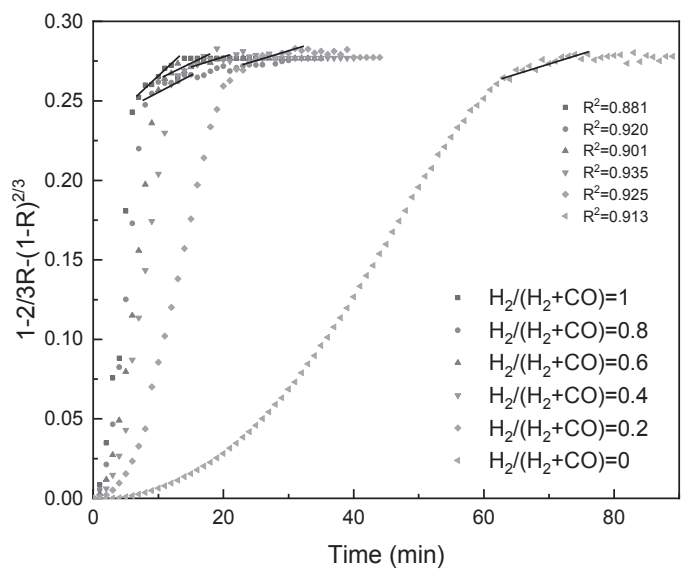

Fig. 13 Relationship between $1-\frac{2}{3} \mathrm{R}-(1-\mathrm{R})^{\frac{2}{3}}$ and time, $\mathrm{t}$, under different atmospheres at $1373 \mathrm{~K}$.

As shown in Table 5, the reaction rate constant increases as $\mathrm{H}_{2} /\left(\mathrm{H}_{2}+\mathrm{CO}\right)$ increases. Therefore, increasing the amount of $\mathrm{H}_{2}$ can effectively improve the reducing ability of the oxidized pellets.

Table 5 Oxidation pellet reduction rate constants for different gas compositions at $1373 \mathrm{~K}$.

\begin{tabular}{lllllll}
\hline $\mathrm{H}_{2} /\left(\mathrm{CO}+\mathrm{H}_{2}\right)$ & 0 & 0.2 & 0.4 & 0.6 & 0.8 & 1 \\
Interface reaction control & 0.01210 & 0.03579 & 0.06034 & 0.07173 & 0.08591 & 0.10647 \\
Diffusion control & 0.00104 & 0.00128 & 0.00224 & 0.00256 & 0.00268 & 0.00284 \\
\hline
\end{tabular}




\section{Conclusions}

In this paper, the gas reduction of pure oxidized limonite pellets in $\mathrm{H}_{2}$ and $\mathrm{CO}$ atmospheres was systematically studied over a temperature range of $973 \mathrm{~K}-1273 \mathrm{~K}$. The degree of reduction increased with time and temperature. The kinetic model successfully simulated the shrinking unreacted nuclear model during the reduction process. For the entire reduction process, kinetic studies have indicated that there are early and late stages, which are controlled by interfacial chemical reactions and diffusion, respectively. The activation energies of $\mathrm{H}_{2}$ atmosphere reduction were $77.87 \mathrm{~kJ} / \mathrm{mol}$ and 38.99 $\mathrm{kJ} / \mathrm{mol}$, respectively, for early and late reduction. In $\mathrm{CO}$, the activation energies of the two stages were $64.53 \mathrm{~kJ} / \mathrm{mol}$ and $44.59 \mathrm{~kJ} / \mathrm{mol}$, respectively. As the ratio of $\mathrm{H}_{2} /\left(\mathrm{CO}+\mathrm{H}_{2}\right)$ increases, the reaction rate constant gradually increases, and the reduction time is gradually shortened. The SEM results show that the particles reduced in $\mathrm{H}_{2}$ have many micropores in the mineral particles, and the microstructure is looser than the particles reduced in CO. The inner hole reduces the gas diffusion resistance, and the activation energy of the pellets in $\mathrm{H}_{2}$ during the diffusion control process is lower than the activation energy of reduction of the pellets in $\mathrm{CO}$.

\section{Acknowledgments}

Project funded by the Ministry of Education of Yunnan Province (Grant: KKJB201752017), Industrial Development Project of Yunnan Provincial Department of Education Science Research Fund (Grant: 2016CYH07), Yunnan Science and Technology Plan Project (Grant: 2017ZE033).

\section{REFERENCES}

1) M.K. Mohanty, S. Mishra and B. Mishra: Arab. J. Sci. Eng. 43 (2018) 5989-5998.

2) S. Mishra and G.G. Roy: Ironmak. Steelmak. 45 (2018) 426-433.

3) Y. Man and J. Feng: Powder Technol. 301 (2016) 1213-1217.

4) G. Chen, W. Hwang and S. Liu: Mater. Trans. 56 (2015) 550-555.

5) K. Zhang, Y. Ge and W. Guo: Vacuum 167 (2019) 163-174.

6) F. Wu, Z. Cao and S. Wang: J. Clean. Prod. 171 (2018) 831-843.

7) A. Kasai and Y. Matsui: ISIJ Int. 44 (2004) 2073-2078.

8) Q. Meng, J. Li and R. Wei: Iron Steel Res. 25 (2018) 1105-1112.

9) Z. Di, Z. Li and R. Wei: Ironmak. Steelmak. 46 (2019) 159-164.

10) Q. Hu, D. Yao and Y. Xie: Energy Convers. Manage. 158 (2018) 1-8.

11) H. Ono, T. Yonezawa and T. Usui: ISIJ Int. 43 (2003) 1502-1511.

12) T. Murakami and E. Kasai: ISIJ Int. 51 (2011) 9-13.

13) K. Abe, A. Kurniawan and T. Nomura: J. Energy Chem. 27 (2018) 1489-1495.

14) R. Sah and S.K. Dutta: Trans. Indian Inst. Met. 64 (2011) 583-591.

15) Y. Lu, Z. Wei and Y. Wang: Powder Technol. 352 (2019) 240-250.

16) H. Ono, Y. Dohi and Y. Arikata: ISIJ Int. 49 (2009) 722-728.

17) T. Murakami, T. Nishimura and E. Kasai: ISIJ Int. 49 (2009) 16861693.

18) Z. Xue: Introduction to Iron and Steel Metallurgy, (Metallurgical Industry Press, Beijing, 2014) pp. 70-71.

19) Y. Sui, Y. Guo and T. Jiang: Alloy. Compd. 706 (2017) 546-553.

20) Y. Sui, Y. Guo and T. Jiang: Miner Metall Mater. 24 (2017) 10-17.

21) Z. Zhu, W. Zhang and C.Y. Cheng: Hydrometallurgy 113-114 (2012) $155-159$.

22) L. Yi, Z. Huang and H. Peng: Cent South Univ. 19 (2012) 2291-2296.

23) Y. Sui, Y. Guo and T. Jiang: J. Alloy. Compd. 706 (2017) 546-553.

24) J. Chen, W. Chen and L. Mi: Metals 9 (2019) 1-13.

25) Y. Wang: Ferrous Metallurgy (Ironmaking), (Metallurgical Industry Press, Beijing, 2005) pp. 87-95.

26) L. Yi, Z. Huang and H. Peng: Cent South Univ. 19 (2012) 2291-2296.

27) T. Usui, M. Ohmi and S. Kaneda: ISIJ Int. 31 (1991) 425-433. 